Meta

Journal des traducteurs

Translators' Journal

\title{
La révision, aspects théoriques et perspectives
}

\section{Anne-Marie Gagné}

Volume 60, numéro 2, août 2015

$60^{\mathrm{e}}$ anniversaire. Les horizons de la traduction : retour vers le futur

$60^{\text {th }}$ Anniversary. Translation's Horizons: Back to the Future

60mo aniversario. Los horizontes de la traducción: regreso al futuro

URI : https://id.erudit.org/iderudit/1032885ar

DOI : https://doi.org/10.7202/1032885ar

Aller au sommaire du numéro

\section{Éditeur(s)}

Les Presses de l’Université de Montréal

ISSN

0026-0452 (imprimé)

1492-1421 (numérique)

Découvrir la revue

Citer ce document

Gagné, A.-M. (2015). La révision, aspects théoriques et perspectives. Meta, 60(2),

334-334. https://doi.org/10.7202/1032885ar d'utilisation que vous pouvez consulter en ligne.

https://apropos.erudit.org/fr/usagers/politique-dutilisation/ 


\title{
La révision, aspects théoriques et perspectives
}

\author{
Anne-Marie Gagné \\ Université de Montréal, Montréal, Canada \\ anne-marie.gagne@umontreal.ca
}

En traductologie, les rares considérations théoriques quant à la révision d'une traduction en vue d'une nouvelle diffusion ont émergé en raison des liens très étroits qu'entretient cette activité avec la retraduction. Toutefois, peu de recherches lui ont été entièrement consacrées. L'étude comparative de la traduction française (Plon, Paris, parue en 1985 pour les deux premiers tomes, puis en 1988 pour le troisième) et de la révision (Lux éditeurs, Montréal, parue en 2013) de Memoria del fuego, trilogie historico-littéraire d'Eduardo Galeano (parue en espagnol uruguayen en 1982, 1984 et 1986), se veut un premier pas dans l'exploration des multiples questions énoncées par nos prédécesseurs. Quels sont les motifs qui mènent à l'entreprise d'un projet de révision? Constitue-t-elle réellement un premier pas vers la retraduction? Peut-on la distinguer de cette dernière au moyen de critères purement quantitatifs? Notre travail, qui s'appuie sur un cadre théorique empruntant des éléments de réflexion à la philosophie poststructuraliste et au courant interactionniste en sociologie, met en évidence le rôle décisif de la réviseure et de la maison d'édition sur l'entreprise de ce type de projet, son déroulement et ses résultats. À partir d'une méthodologie alliant les perspectives textuelle et contextuelle, l'analyse de la révision de Mémoire $d u$ feu révèle la nécessité de se pencher sur les pratiques en milieu éditorial, de même que sur les conceptions des agents qui participent au processus de révision.

Anne-Marie Gagné est candidate à la maîtrise en traduction à l'Université de Montréal. Ses recherches actuelles en traductologie portent sur les pratiques relatives à la révision en vue d'une nouvelle publication et à la retraduction. Elle porte un intérêt particulier à l'aspect sociologique de la traduction et aux liens qu'elle entretient avec la culture et l'idéologie. Elle est aussi auxiliaire de recherche en terminologie à l'Observatoire de linguistique Sens-Texte où elle a élaboré un cadre théorique relatif à l'antonymie dans cette discipline. 